\title{
Sustainable Aquafeed: Alternative Ingredients Produced Locally as Nutrient Complementary in Minimizing the Use of Fishmeal
}

\author{
Noor Khalidah Abdul Hamid \\ School of Biological Sciences, Universiti Sains Malaysia, Pulau Pinang Malaysia. \\ Corresponding author.Email: khalidah.hamid@usm.my
}

\begin{abstract}
Exploring cost-effective animal-derived protein alternatives is very important to support the growing human population with food resources globally. Aquaculture has significant contribution to this sector by providing fish and fishery products. This article provides short review on aquafeed, one of important aspects for the sustainable aquaculture production.
\end{abstract}

Keywords:Aquaculture, Aquafeed, Fishmeal, Protein, Insect

\section{INTRODUCTION}

Aquaculture has made significant contributions to global food security and nutrition by providing fish and fishery products as cost-effective animal-derived protein alternatives to support the growing human population with food resources. The sector is responsible for the continuing growth in the supply of food fish for human consumption [1]. Thus, more feed resources are required for sustaining the growth of aquaculture. In the year 2008, approximately 31.5 million tonnes (46.1\% of total global farmed aquatic animals and plants production) of farmed fish and crustaceans, not including filter-feeding fish species and some other freshwater species produced globally depend on external nutrient input in the form of feed either in the form of fresh feed items, farm-made or commercial pellets [2]. The growth in fed species aquaculture over the years stimulated the growth of aquaculture feed production, resulting in the total production of commercial aquaculture feed increasing tremendously by nearly fourfold from 7.6 million tonnes in 1995 to 27.1 million tonnes in 2007, growing at an average annual rate of $11.1 \%$ and is expected to continue to grow at a similar rate to 70.9 million tonnes by 2020 [2]. Although the global pandemic disrupted the entire economic chain of the aquaculture cycle from production to the consumer, aquafeed sustainability's dilemma continues to be a challenge. Following the spread of Covid-19 in 2019, the aquaculture industry is shifting from shock to embracing the current situation and adapting to alternative marketing strategies by focusing on the local market [3].

\section{AQUAFEED FORMULATION}

Aquafeed is formulated to have balance in nutritional compound requires by the culturing fish species. Sixty to $70 \%$ of the operational cost of aquaculture is due to the feed. Fish requires essential nutrients such as amino acids, fatty acids, vitamins, minerals and energy-yielding macronutrients (protein, lipid and carbohydrates) [4]. All of these must be supplied through the diet of the fish to meet the physiological needs for growing and reproduction [4]. Protein is an essential part of the fish diet as it supplies the essential amino acids and the most expensive portion of the diet [4]. Arginine, histidine, isoleucine, leucine, lysine, methionine, phenylalanine, threonine, tryptophan, and valine are the ten essential amino acids needed by most of the fish species based on studies done to date [4]. Although fish show no dietary requirement towards carbohydrates, the availability of carbohydrates in the fish diet will result in protein and lipid sparing depending on fish species as some fish, especially herbivores and omnivores, can utilize carbohydrates as energy sources. At the same time, the ability to do so is limited for carnivorous species, meaning carnivorous species will utilize a higher portion of protein and lipid in their diet to be catabolized for energy [4]. However, polysaccharides such as cellulose, hemicellulose and chitin, which are 
non-starch, are generally indigestible for most fish species [4]. Nutrient digestibility in feed given to fish plays a vital role in aquaculture production and its impacts on the environment [5]. Only the digestible proportion of the feed given to the fish will be digested and absorbed by the fish, while the rest of the indigestible proportion of nutrients will be excreted as feces and pollute the environment indigestible proportion is high in nutrients [5]. On the other hand, lipids in the fish diet are responsible for supplying essential fatty acids and energy and acting as precursors of steroid hormones and prostaglandins in fish and aid in the intestinal lipid-soluble vitamins absorption [4]. Ensuring that most of the essential nutrient included in the formulation, raw ingredients such as fish meal is a must.

\section{AQUAFEED SUSTAINABILITY}

Fishmeal is the most commonly used raw materials, and it is a preferred ingredient. It is mainly derived from wild-caught whole fish, while a minor part of the fishmeal supply is from processing by-products of fish such as fish offal and trimmings [2]. Fish caught from fisheries used to produce fishmeal are usually small, bony, and oily and not used by humans for consumption [6]. A good quality fish meal usually contains 60 to 72 per cent crude protein, making it an excellent choice of ingredient to be used in the feed from a nutritional point of view [6]. One of the main features of fishmeal separates it from other protein sources because it contains all the essential amino acid and has long-chain polyunsaturated omega-3 fatty acids [6,7]. Due to its high-quality protein content, high digestibility, minerals and vitamin content and amino acid composition, fishmeal has been considered a premium or gold standard ingredient in aquafeed, and that place never been challenged $[6,7]$.

The limited fishmeal supply, which has been relatively stagnant over the past 15 years and is very unlikely to increase further, coupled with high demand and public pressure on sustainable aquafeed, questions the long term sustainability of fishmeal [2,8]. In addition to that, limited ocean stocks have resulted in higher prices and reduced fishmeal availability [9-11]. Hence, heavy reliance on this finite resource may limit aquaculture's growth soon as fluctuations in global demand and supply of fish meal have resulted in the increasing cost and scarcity of the material. These have made the long-term sustainability of aquaculture questionable, as the use of fishmeal in aquafeed production is becoming unjustifiable in the economic sense, and it will undoubtedly affect the growth and profitability of the sector. Hence, the identification and development of feed ingredients alternative to fishmeal are internationally recognized as a research priority to ensure sustainable growth for aquaculture production [8]. Therefore, it is imperative to develop sustainable alternatives for feed production. The use of alternative feed ingredients is intended to reduce the dependency on the scarce, expensive, and unsustainable ingredient, thereby maximizing profit.

Globally, people are seeking alternative ingredients to fishmeal for a total or partial replacement. The potential use of alternative ingredients to the fishmeal has been tested in a pilot-scale up to a commercial scale to verify these aquafeed ingredients' suitability. Sources of animal-based protein such as meat and bone meal, blood meal, poultry by-product meal and feather meal are widely used in fish diet to partially or fully replace fishmeal in some fish diets when several ingredients are combined [12]. The problems with using animal-based protein are insufficient essential amino acid, the inconsistent supply and availability of blood meal, low digestibility as seen in feather meal and inconsistent nutritional content because they are affected by processing condition [12].

Plant-based protein is a promising alternative ingredient to fishmeal as they are a lot cheaper than fishmeal, and a study had shown that it is possible to replace fishmeal completely by using plant protein only in the diet of Nile tilapia without any significant reduction in growth [13]. However, for some other fish species, increasing plant-based protein and reducing fishmeal inclusion will decrease their feed intake due to lower palatability and reduce growth [13]. Another study showed that plant protein from soybean meal could only be substituted up to 60 per cent of fishmeal without affecting African catfish growth [14]. Nevertheless, plant protein ingredients are still inferior to fishmeal. Soybean meal contains antinutritional factors, lacking in certain essential amino acids, low nutrient digestibility, low palatability and a high indigestible fibre by most fish [13]. Protein extracts from oilseeds and cereals are higher in protein than meals and edible seeds of plants in the legume family and lower in antinutritional factor but are more expensive, limiting their use in aquafeed [15]. In addition to that, the aquatic macrophyte Azolla has high potential as an aquafeed ingredient. It is a nitrogenfixing frond and capable of photosynthesizing at a higher rate than most $\mathrm{C} 4$ plants. Azolla grows well in the paddy field and water channel with a warm climate. Studies showed that Azolla could be incorporated up to 30 in tilapia's diet without adverse effect on growth. Unlike most protein-plant, Azolla does not require much cost to produce. Research at the International Rice Research Institute in the Philippines has shown in 
laboratory studies that Azolla can double its weight in 3-5 days, grow in nitrogen-free solution and accumulate 30 to $40 \mathrm{~kg} \mathrm{Na} \mathrm{ha}^{-1}$ in two weeks. This feature is making Azolla a sought after material to grow fish, especially in south-east Asia.

In the last decade, there has been a surge of interest in using insects as a protein source in animal feed production [10]. In most parts of the world, the value of insects as a source of fish feed is underappreciated $[10,16]$. Insects are rich in protein, and several studies have shown that they can be used as an alternative for fishmeal in fish diets. However, studies on omnivorous species are more than carnivorous ones [17,18]. The outcome from most of the experiment trials suggest a replacement rate of less than 25 to 30 per cent, and on the other hand, in several studies, total replacement of fishmeal with insect meal is found to be technically and economically feasible [17]. One of the aquafeed industry's main priorities is seeking alternative fishmeal ingredients to ensure the sector's sustainability [19]. Among the potential alternatives to conventional feed materials, insects, particularly the hermetia larvae. Hermetia larvae are nutrient enhancer or mediator that have the potential of replacement fishmeal. Its ability to convert food waste (vegetable, fruit, factory waste, and animal tissues) into high-quality protein, and as such, industrial-scale production has grown in the past decade [20]. Using hermetia larvae meal in aquafeed will contribute to circular economic growth, agro-waste residual management and aquafeed sustainability.

Sustainable aquafeed is about reducing the inclusion of fishmeal in the aquafeed formulation, using sustainable resources, making the aquafeed affordable for the farmers. Fishmeal is harvested from the open ocean, given by nature almost at no cost. However, plant protein requires land use and other animal protein waste-derived and missing essential amino acids and fatty acid content. Total exclusion of fishmeal from the aquafeed formulation is not helpful to neither ecology nor economy sustainability [21]. Thus, having locally available alternative ingredients is essential for developing countries such as Malaysia and Indonesia. This because these ingredients could complement the missing nutrient profile while reducing the inclusion of fishmeal in the feed and reduce the reliance on imported raw ingredients subject to currency exchange.

\section{CONCLUSION}

Aquaculture role in supporting food supplay in the current increased global human populaton has been prominent. This role, however, must be supported by a sustainable aquadfeed production that requires appropriate formulation and the use of locally alternative raw materiasl due to nutritional and economical considerations.

\section{ACKNOWLEDGMENT}

I thank the Malaysian Research Universities Network Translational Research Grant to support the study on alternative ingredients for aquafeed using local resources.

\section{REFERENCES}

[1] FAO, The State of World Fisheries and Aquaculture, Sustainability in Action, Rome, 2020.

[2] A.G.J. Tacon, M.R. Hasan, M. Metian, Demand and supply of feed ingredients for farmed fish and crustaceans: Trends and prospects, Food and Agriculture Organization, FAO Fisheries and Aquaculture Technical Paper No. 564, Rome, 2011.

[3] D. Love, E.H. Allison, F. Asche, B. Belton, R. Cottrell, H. Froehlich, J. Gephart, C.C. Hicks, D.C. Little, E.M. Nussbaumer, P. da Silva, F. Poulain, A. Rubio, J. Stoll, M.F. Tlusty, A.L. Thorne-Lyman, M. Troell, W. Zhang, Emerging COVID-19 impacts, responses, and lessons for building resilience in the seafood system. https://osf.io/preprints/socarxiv/x8aew/ (2020) 122.

[4] S.P. Lall, S.M. Tibbetts, Nutrition, feeding, and behavior of fish, Veterinary Clinic of North America, Exotic Animal Practice, 12(2) (2009) 361-372.

[5] S. M. Hixson, Fish nutrition and current issues in aquaculture: The balance in providing safe and nutritious seafood, in an environmentally sustainable manner. J. Aquacult. Res. Dev. 5 (2014) 234.

[6] J. Cho, I. Kim, Fish meal - Nutritive value. J. Anim. Physiol. Anim. Nutr. 95 (2011) 685-692

[7] G.M. Turchini, J.T. Trushenski, B.D. Glencross, Thoughts for the future of aquaculture nutrition: realigning perspectives to reflect contemporary issues related to judicious use of marine resources in aquafeeds. North Am. J. Aquacult. 81(1) (2019) 13-39.

[8] M. Boonyaratpalin, Overview on the use of plant protein in aquaculture feed. In M.R. Catacutan, R.M. Coloso, B.O. Acosta (Eds.), Development and use of alternative dietary ingredients or fish meal substitutes in aquaculture feed formulation, Proceedings of the ASEAN Regional Technical 
Consultation on Development and Use of Alternative Dietary Ingredients or Fish Meal Substitutes in Aquaculture Feed Formulation, 9-11 December 2014, Nay Pyi Taw, Myanmar (pp. 105107). Tigbauan, Iloilo, Philippines: Aquaculture Department, Southeast Asian Fisheries Development Center.

[9] A.G.J. Tacon, M. Metian, Industrially compounded aquafeeds: Trend and future prospects, Aquaculture 2885(1) (2008) 146-158. DOI: 10.1016/j.aquaculture.2008.08.015

[10] A. van Huis, Potential of Insects as food and feed in assuring food security, Ann. Rev. Entomol. 58(1) (2013)565-583.

DOI: https://doi.org/10.1146/annurev-ento-120811153704

[11] F.J. Fawole, A.A. Adeoye, L.O. Tiamiyu, K.I. Ajala, S.O. Obadara, I.O. Ganiyu, Substituting fishmeal with Hermetia illucens in the diets of African catfish (Clarias gariepinus): Effects on growth, nutrient utilization, haemato-physiological response, and oxidative stress biomarker. Aquaculture 518 (2020) 734849.

[12] F.Y. Ayadi, K.A. Rosentrater, K. Muthukumarappan, Alternative protein sources for aquaculture feeds. J. Aquacult. Feed Sci. Nutr. 4(1) (2012) 1-26.

[13] N. Daniel, A review on replacing fish meal in aqua feeds using plant protein sources, Int. J. Fisheries Aquatic Studies 6 (2018) 164-179.

[14] U.D. Enyidi, Production of feeds for African catfish Clarias gariepinus using plant proteins,
Finland, Jyvaskyla, University of Jyvaskyla, Jyvaskyla Studies in Biological Studies 251, 2012.

[15] M. Francoise, K. Sadasivam, Protein sources in feed for farmed fish. Cahiers Agric. 18(2) (2009) 103-111.

[16] H.P.S. Makkar, G. Tran, V. Heuze, P. Ankers, State-of-the-art on use of insects as animal feed. Anim. Feed Sci. Technol. 197(0) (2014) 1-33. DOI: http://dx.doi.org/10.1016/j.anifeedsci.2014.07.008

[17] G. Tran, V. Heuzé, H.P.S. Makkar, Insects in fish diets. Animal Frontiers 5(2) (. 2015.) 37-44.

[18] E.W. Riddick, Insect protein as a partial replacement for fishmeal in the diets of juvenile fish and crustaceans, In Mass Production of Beneficial Organisms, 1st Ed., J. Morales-Ramos, D. Shapiro-Ilan, G.M. Rojas (Eds) (2014) pp. 565582. DOI: 10.1016/B978-0-12-391453-8.00016-9.

[19] S. Castillo, D.M. Gatlin, Dietary supplementation of exogenous carbohydrase enzymes in fish nutrition: A Review, Aquaculure 435 (2015) 286292. DOI: 10.1016/j.aquaculture.2014.10.011

[20] H. Fisher, S. Collins, C. Hanson, B. Mason, S. Colombo, D, Anderson, Black soldier fly larvae meal as a protein source in low fish meal diets for Atlantic salmon (Salmo salar). Aquaculture 521 (2020) 734978.114, 184.

[21] G.M. Turchini, J.T. Trushenki, B.D. Glencross, Thoughts for the future of aquaculture nutrition: Realigning perspectives to reflect contemporary issues related to judicious use of marine resources in aquafeeds, North Am. J. Aquacult. (81 (2019) 13-39 2018 DOI: https://doi.org/10.1002/naaq.10067 